\title{
Research Article \\ Meteodiffusive Characterization of Algiers' Nuclear Research Reactor
}

\begin{abstract}
Mourad Messaci
Received 27 January 2007; Accepted 29 March 2007

Recommended by Giorgio Galassi

In the framework of the environmental impact studies of the nuclear research reactor of Algiers, we will present the work related to the atmospheric dispersion of releases due to the installation in normal operation, which dealt with the assessment of spatial distribution of yearly average values of atmospheric dilution factor. The aim of this work is a characterization of the site in terms of diffusivity, which is basic for the radiological impact evaluation of the reactor. The meteorological statistics result from the National Office of Meteorology and concern 15 years of hourly records. According to the nature and features of these data, a Gaussian-type model with wind direction sectors was used. Values of wind speed at release height were estimated from measurement values at $10 \mathrm{~m}$ from ground. For the assessment of vertical dispersion coefficient, we used Briggs' formulas related to a sampling time of one hour. Areas of maximum impact were delimited and points of highest concentration within these zones were identified.
\end{abstract}

Copyright (c) 2007 Mourad Messaci. This is an open access article distributed under the Creative Commons Attribution License, which permits unrestricted use, distribution, and reproduction in any medium, provided the original work is properly cited.

\section{INTRODUCTION}

This work is related to the field of radiological impact assessment on population of nuclear facilities. In this framework, the Nur research reactor situated near Algiers was subject to environmental impact studies.

In this paper, we present the work related to the meteodiffusive characterization of the reactor site dealing with the assessment of spatial distribution of annual averaged atmospheric dilution factor (ADF).

Atmosphere is the main vector of radioactivity transfer to population, then the results of this study are the basis to radiological impact assessment of Nur reactor.

\section{SITE DATA}

Nur is a $1 \mathrm{MW}$ open pool, light water, LEU (low enriched uranium), MTR (material test reactor) type research reactor, with a $30 \mathrm{~m}$ height for the stack. It is located at $200 \mathrm{~m}$ altitude, in a rural area situated at $10 \mathrm{~km}$ from the city centre [1].

The meteorological data, provided by the National Office of Meteorology, concern a period of 15 years and consist of 122663 hourly observations of wind speed and direction as well as atmospheric stability class [2].

These data are grouped by wind direction sectors and show that the north direction, with a frequency of 0.346 is the most relevant wind direction, followed by the west direction with a frequency of 0.119 .

Regarding atmospheric stability, a predominance of stability class with a frequency of 0.513 occurs, followed by neutral conditions with a frequency of 0.352 .

\section{METHODOLOGY}

According to the nature and features of meteorological data supplied by the National Office of Meteorology, we adopted a Gaussian-type atmospheric dispersion model with wind direction sectors.

In a wind direction sector $i$ and at a distance $X$ from the installation point, the mean annual value $\operatorname{ADFi}(X)$ of atmospheric dilution factor (expressed in $\mathrm{s} \cdot \mathrm{m}^{-3}$ ) is given by [3]

$$
\operatorname{ADF}_{i}(X)=\sum_{j=1}^{6} \sum_{k=1}^{6} \operatorname{ADF}_{i j k}(X) \cdot f_{i j k}
$$

In this expression, $f_{i j k}$ is annual frequency of wind occurrence in the $i$ sector with a wind speed class $j$ and atmospheric class stability $k(k=1$ for $A, k=2$ for $B, \ldots, k=6$ for $F$ ). The ADF term is the contribution to the mean group speed $j$ and the stability class $k$.

By integrating the dilution factor against $y$ and by taking into account that the result is uniformly distributed along the 

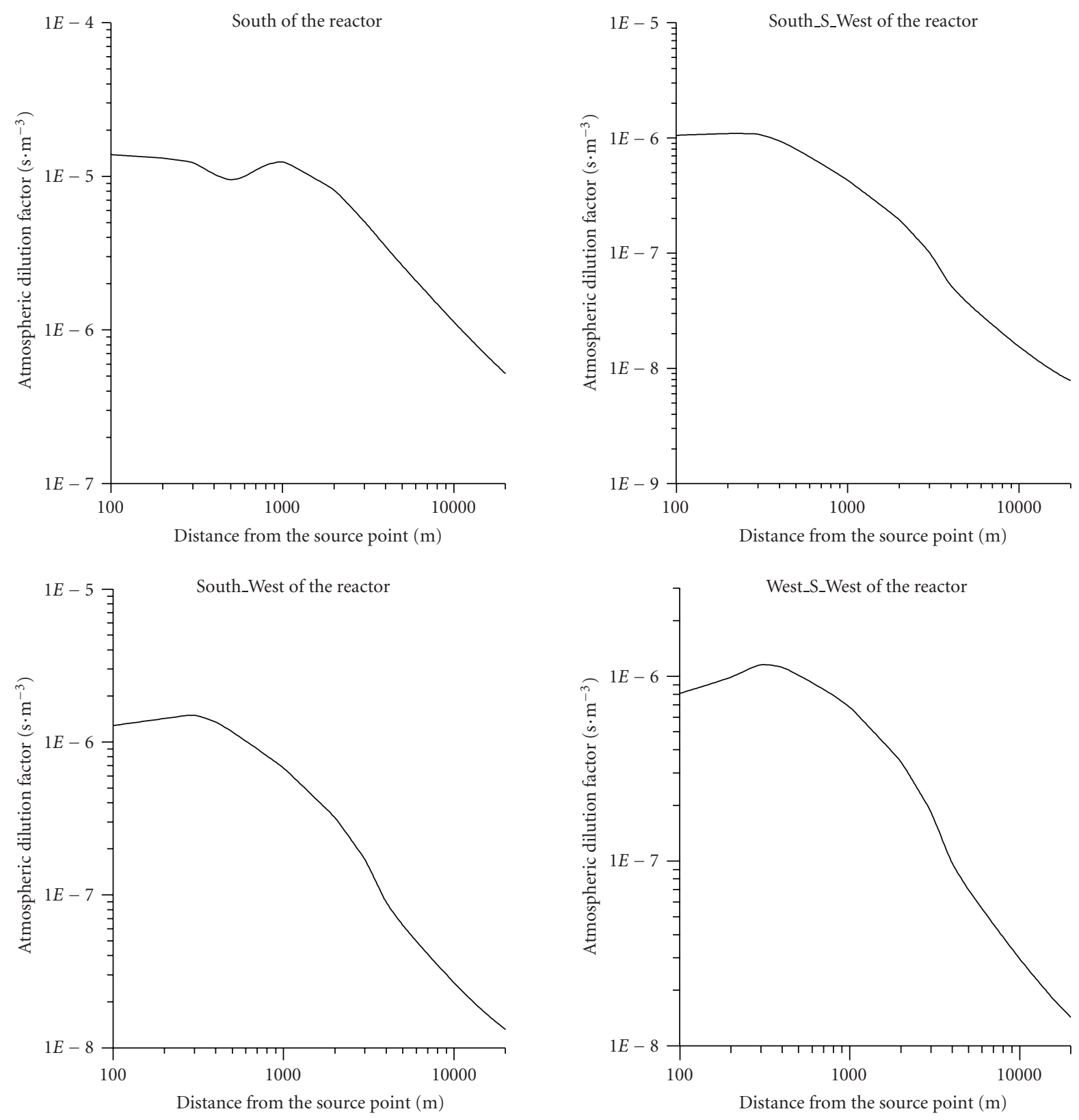

FIgURE 1: Atmospheric dilution factor in the south of the reactor.

delimited arc by the area $i$ at a distance $X$, we obtain the following value of $\mathrm{ADF}_{i j k}(X)$ :

$$
\operatorname{ADF}_{i j k}(X)=\frac{16}{X \pi \sqrt{2 \pi}} \frac{1}{U_{j} \sigma_{z_{k}}} \exp \left(-\frac{H^{2}}{2 \sigma_{z_{k}}^{2}}\right),
$$

where $U_{j}$ is the wind speed at the height of release, $\sigma_{z k}$ is the vertical dispersion factor for stability class $k$, and $H$ is the effective release height.

In this model, $H$ corresponds to the stack height of the reactor $(30 \mathrm{~m})$; this assumption is justified by the fact that since the release occurs at ambient temperature, the plume rise can be neglected.
The value $U_{j}$ of wind speed at the release height is obtained from the characteristic value $U_{j}(10)$ of the $j$ th measured speeds group at $10 \mathrm{~m}$ from the ground by [4]

$$
U_{j}(H)=U_{j}(10)\left(\frac{H}{10}\right)^{p}
$$

where $p$ is a parameter depending on the type of the site and the class stability (see Table 1).

For $\sigma_{z k}$ parameter, we used Briggs' formulas which are related to a sampling time of 10 minutes and distances from $100 \mathrm{~m}$ to $10 \mathrm{~km}$ (see Table 2) [5]. 

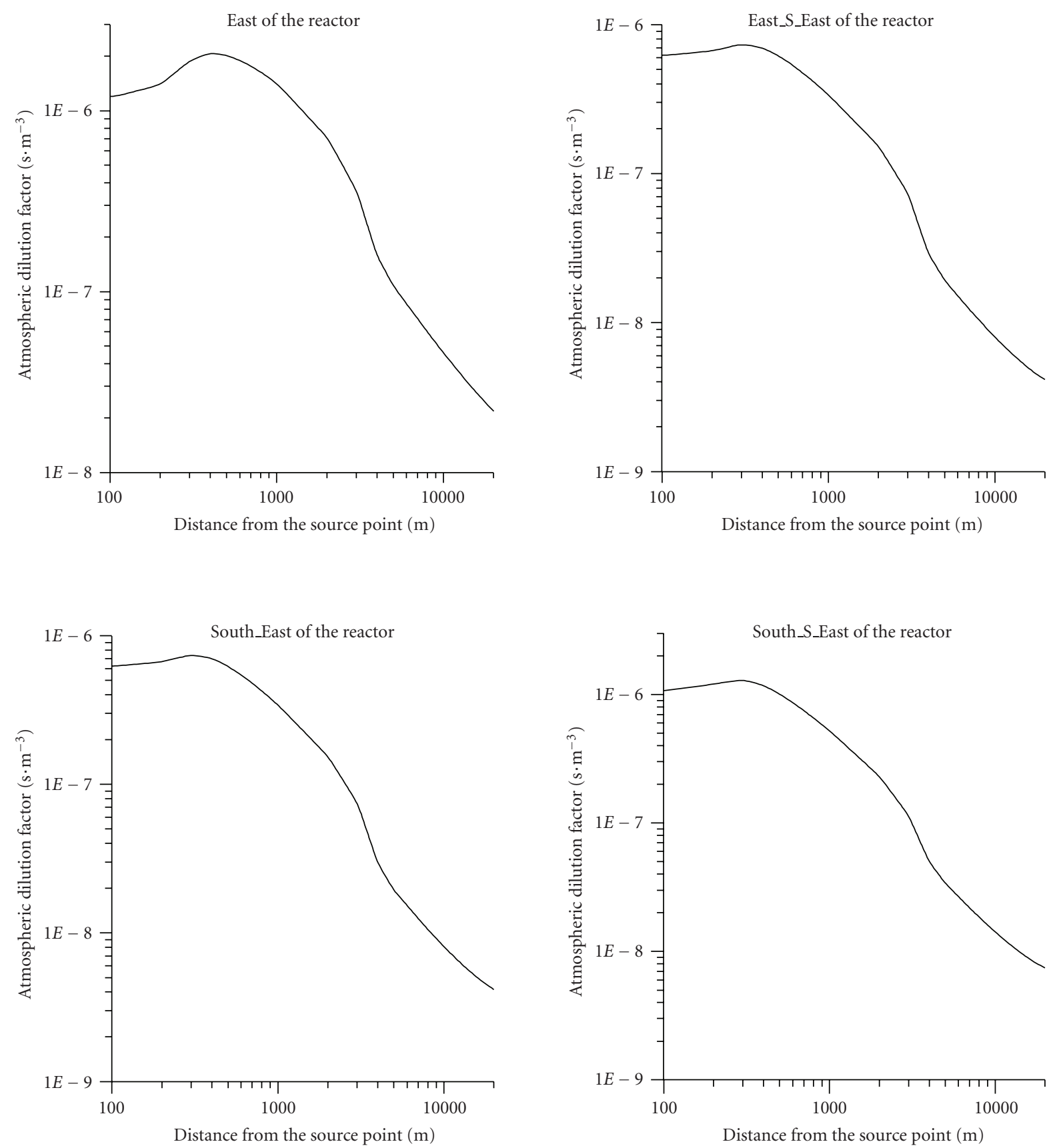

FIgURE 2: Atmospheric dilution factor in the east of the reactor.

Table 1: Values of $p$.

\begin{tabular}{ccc}
\hline Stability class & Urban site & Rural site \\
\hline A & 0.15 & 0.07 \\
B & 0.15 & 0.07 \\
C & 0.20 & 0.10 \\
D & 0.25 & 0.15 \\
E & 0.40 & 0.35 \\
F & 0.60 & 0.55 \\
\hline
\end{tabular}

TABLe 2: Values of $\sigma_{z k}$ parameter.

\begin{tabular}{ccc}
\hline Stability class & Urban site & Rural site \\
\hline A & $0.24 X(1+0.001 X)^{0.5}$ & $0.20 X$ \\
B & $0.24 X(1+0.001 X)^{0.5}$ & $0.12 X$ \\
C & $0.20 X$ & $0.08 X(1+0.0002 X)^{-0.5}$ \\
D & $0.14 X(1+0.0003 X)^{-0.5}$ & $0.06 X(1+0.0015 X)^{-0.5}$ \\
E & $0.08 X(1+0.0015 X)^{-0.5}$ & $0.03 X(1+0.0003 X)^{-1}$ \\
F & $0.08 X(1+0.0015 X)^{-0.5}$ & $0.016 X(1+0.0003 X)^{-1}$ \\
\hline
\end{tabular}



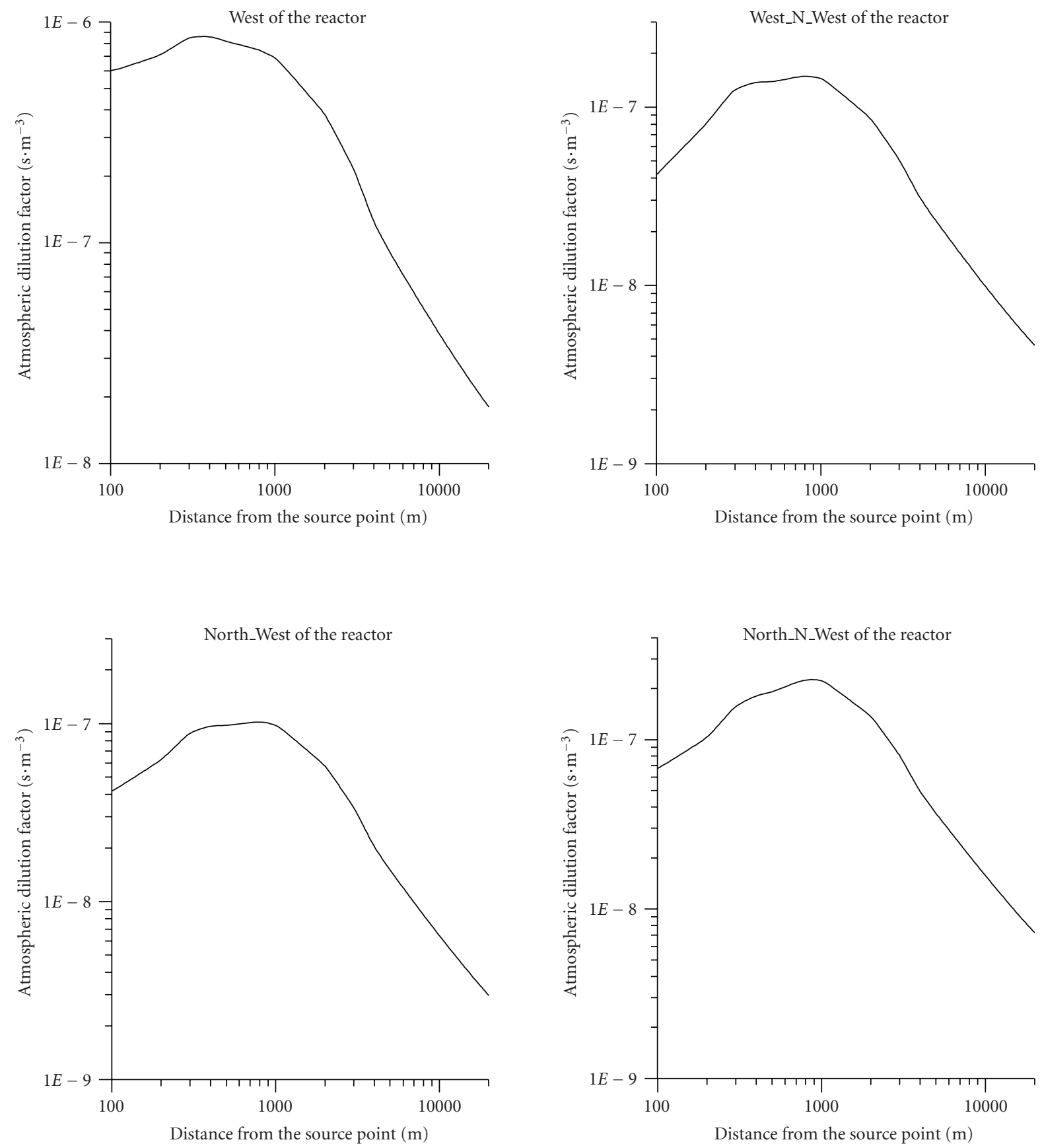

FIgUre 3: Atmospheric dilution factor in the west of the reactor.

For a sampling time different from 10 minutes, $\sigma_{z k}(X)$ can be obtained from the values calculated by Briggs' formulas with the following correction:

$$
\sigma_{z_{k}}(T)=\sigma_{z_{k}}(10 \min )\left(\frac{T}{10}\right)^{\alpha}
$$

where $T$ is the sampling time expressed in minutes and $\alpha$ is equal to 0.2 for $T \leq 1$ hour and 0.3 for 1 hour $\leq T \leq 72$ hours.

\section{RESULTS}

The spatial distribution of ADF on the Nur reactor site was estimated using the ADF programme based on the model presented in Section 3.

Calculation was done for the 16 directional wind areas and Figures 1-4 show the spatial distribution smooth of the ADF around Nur installation.

We can see that the area located on the south of the reactor is by far the most exposed one, with an ADF 1 to 2 orders higher than that of the other sectors. Moreover, this area is 

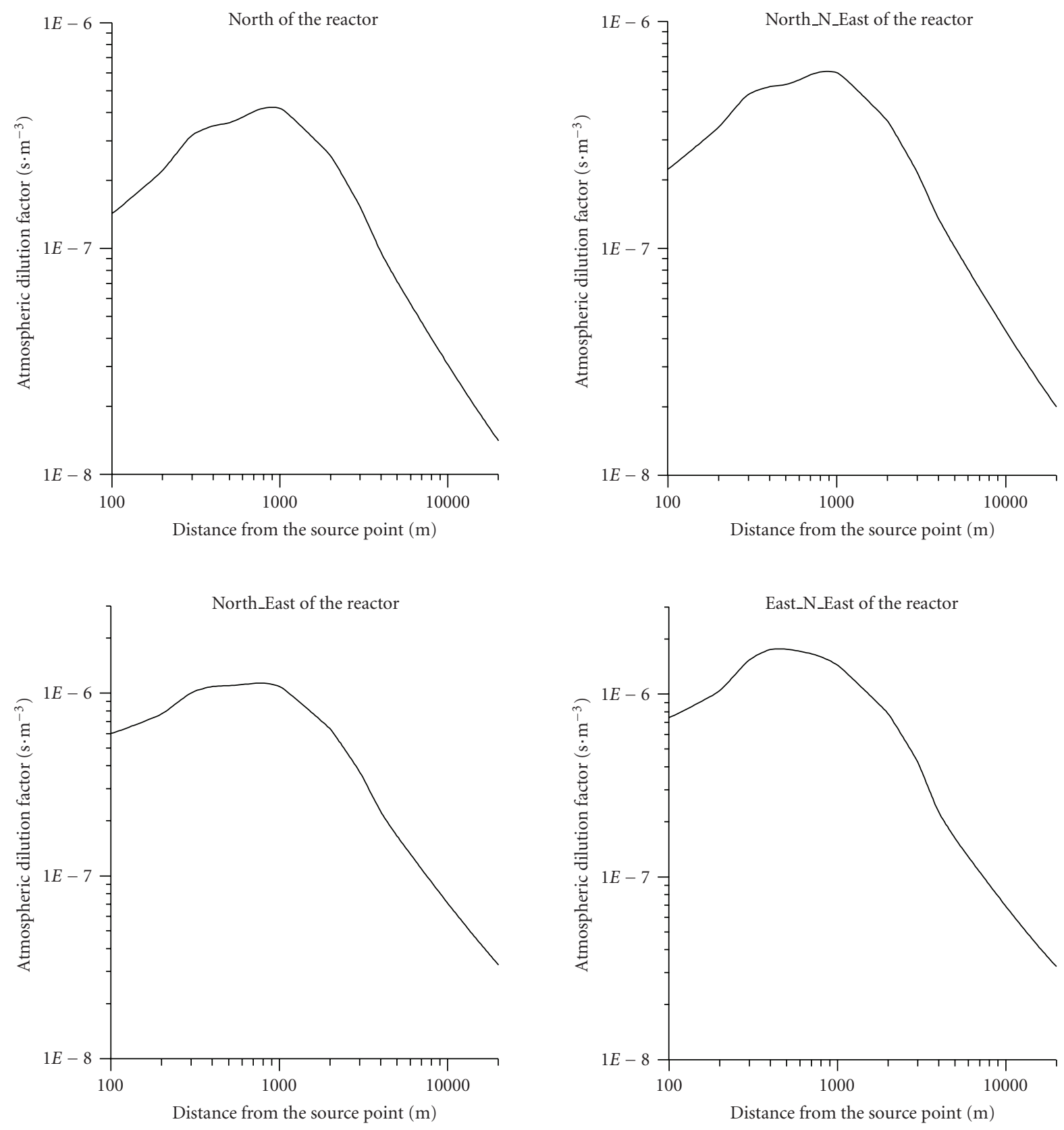

Figure 4: Atmospheric dilution factor in the north of the reactor.

marked by the presence of a peak $1 \mathrm{~km}$ far from the source point, a peak which can be explained by the presence in this area of the strong prevalence of the $F$ stability class known to be favorable for the pollution transport on important distances.

\section{CONCLUSIONS}

This study allowed us to assess, on the basis of a Gaussian dispersion model with directional wind areas and a database on local climatology, the impact of atmospheric releases from the Algiers nuclear research reactor in normal operation.
In a general manner, the maximum impact point is located at a distance ranging from $300 \mathrm{~m}$ to $1 \mathrm{~km}$ from the release point which corresponds to 10 to 30 times the height of the reactor stack. Furthermore, the south of the plant is the most affected area with the biggest atmospheric dilution factors.

\section{REFERENCES}

[1] A. Benchieub and H. Sedfi, "Evaluation de l'impact radiologique de rejets atmosphériques d'une installation nucléaire en fonctionnement normal: modélisation des voies de transfert à l'homme et application au réacteur de recherche Nur," 
Thèse d'Ingéniorat d'Etat, University of Sciences and Technology (USTHB), Alger, Algeria, 1995.

[2] Office National de Météorologie, "Données météorologiques d'Alger," 1971-1988, ONM, Alger, Algeria.

[3] Agence Internationale de l'Energie Atomique, Dispersion atmosphérique et choix des sites de centres nucléaires, Collection sécurité, no. 50-SG-S3, AIEA, Vienne, Austria, 1981.

[4] M. Messaci, "Diffusion sur site côtier en présence de brise," Thèse de Magister, C.R.S., Alger, Algeria, 1987.

[5] F. A. Gifford, "Turbulent diffusion-typing schemes: a review," Nuclear Safety, vol. 17, no. 1, pp. 68-86, 1976.

\section{AUTHOR CONTACT INFORMATION}

Mourad Messaci: Commissariat à l'Energie Atomique, Centre de Recherche Nucléaire d'Alger, 2 Boulevard Frantz Fanon,

BP 399 Alger-Gare, Alger 16000, Algeria; mmessaci@yahoo.fr 

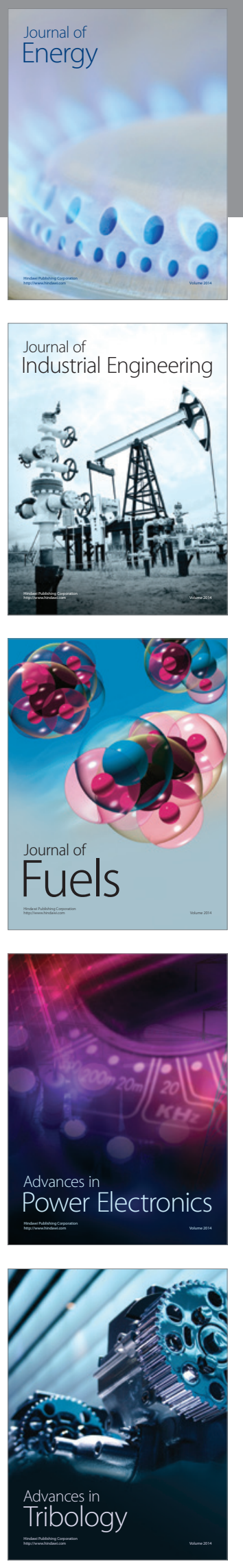
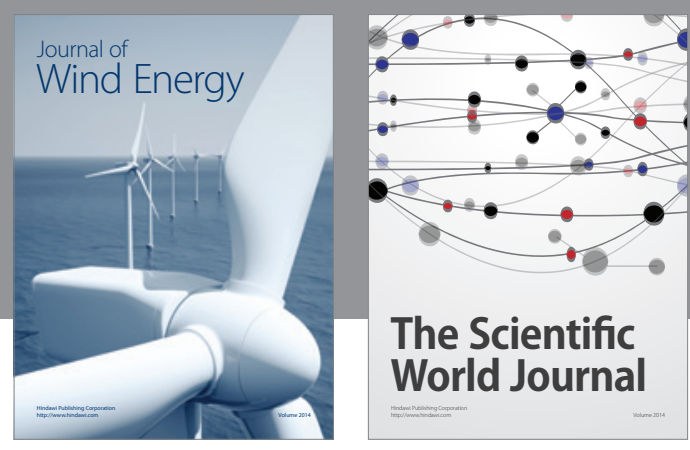

The Scientific World Journal

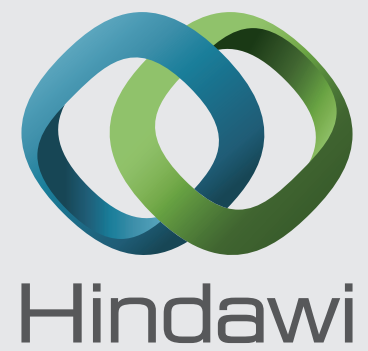

Submit your manuscripts at http://www.hindawi.com
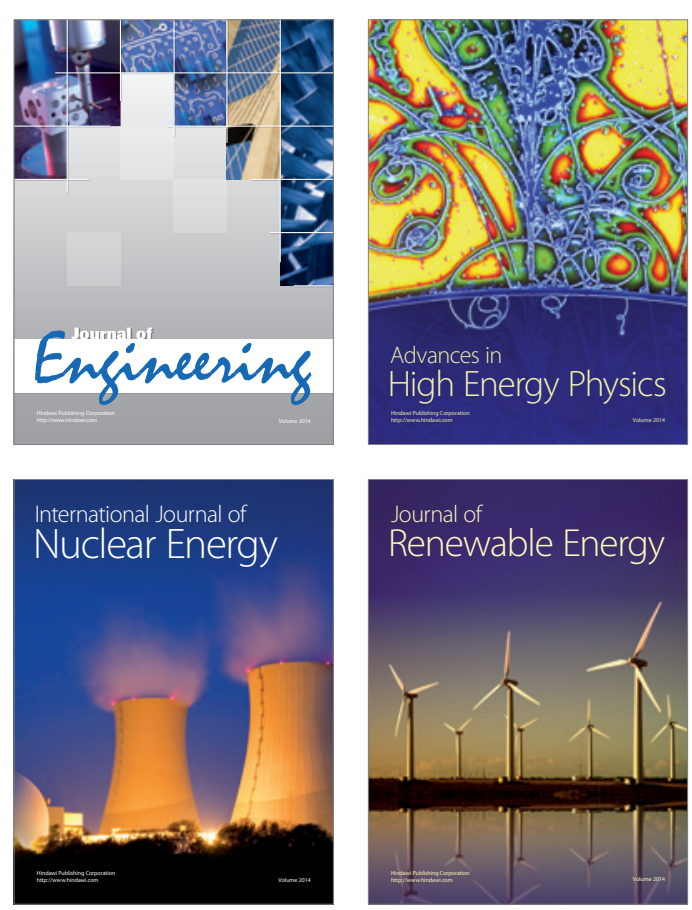

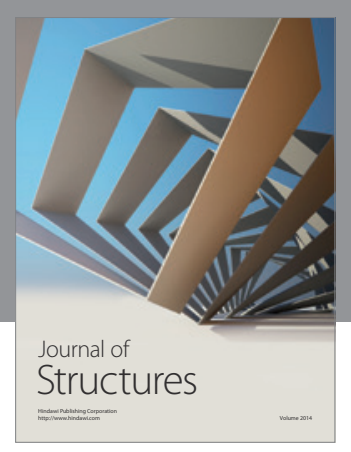

Rotating
Mechinery
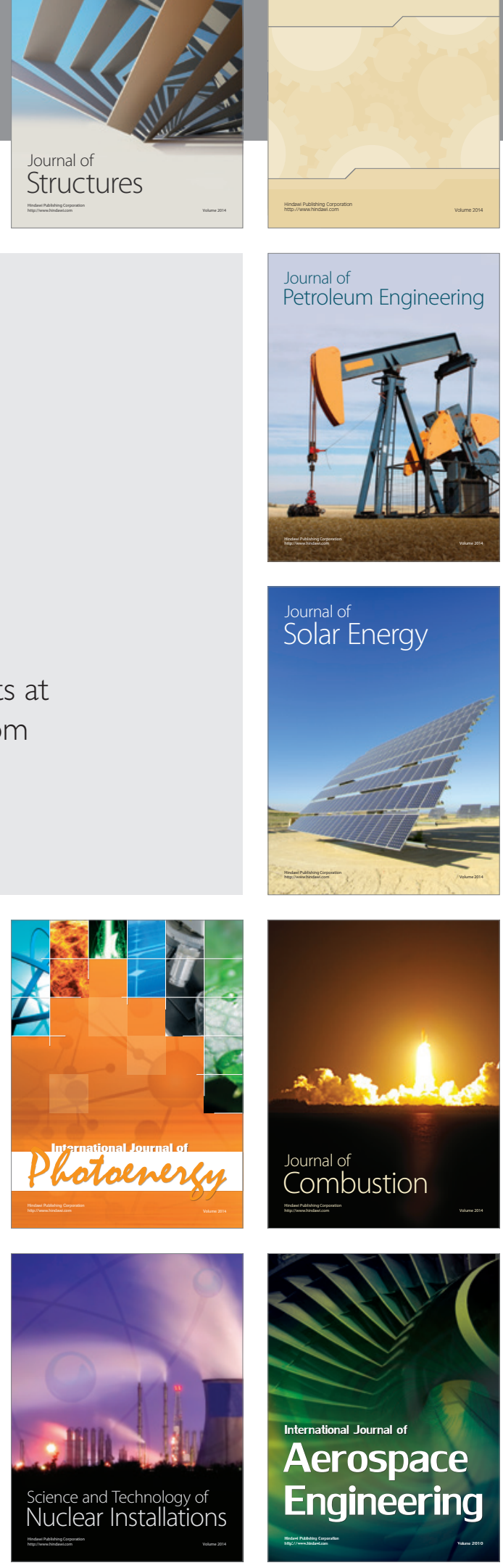